\title{
Reopening Schools After a Novel Coronavirus Surge
}

\author{
Dan Li ${ }^{1}$, Elizabeth Z. Lin ${ }^{1}$, Marie A. Brault ${ }^{1}$, Julie Paquette ${ }^{2}$, Sten H. Vermund 1,* and Krystal J. Godri Pollitt 1,* \\ ${ }^{1}$ Yale School of Public Health \\ 2. Office of Facilities, Yale University \\ *Correspondance: sten.vermund@yale.edu, krystal.pollitt@yale.edu; Tel: 203-785-2867 (S.H.V.); 203-733-1444 \\ (K.J.G.P.); Fax: 203-785-6103 (S.H.V. \& K.J.G.P.)
}

Publisher's Note: MDPI stays neutral with regard to jurisdictional claims in published maps and institutional affiliations.

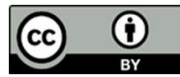

Copyright: (c) 2020 by the authors. Submitted for possible open access publication under the terms and conditions of the Creative Commons Attribution (CC BY) license (http://creativecommons.org/licenses/by/4.0/).

\begin{abstract}
The SARS-CoV-2 pandemic is the worst global respiratory viral emergency since the pandemic influenza of 1918-1919. As of December 2020, nearly 70 million people have been infected and 1.5 million lives have been lost to coronavirus disease 2019 (COVID-19). Schools worldwide were drastically impacted as they closed due to illness and absenteeism, transmission, and risk to vulnerable members of the school community, and community concerns. The decision to reopen school during a pandemic will have important implications for the educational and social well-being of school children, but schools must be kept safe from viral spread to ensure the safety of children, families, and teachers and staff. Keeping schools closed may socially isolate children and provide suboptimal educational experiences, especially for youth with special needs. Lower-income families may have limited computing assets and/or online access. Reopening schools requires careful consideration of benefits, risks, and necessary precautions. Our aim in this paper is to highlight riskmitigation strategies in schools during the COVID-19 pandemic based on our experiences in the United States. These include fundamental principles of disease control requiring school-directed initiatives (physical distancing and mask use, hand/face and surface cleansing, administrative and engineering controls for air quality and outdoor activities). Most risk mitigation approaches depend on individual-level risk reduction based on maximal adherence to guidelines. School-initiated "topdown" approaches and individual-level "bottom-up" approaches must be synergized, as no single method will ensure safety. Safety principles, disease control strategies, and other critical policy issues are key to feasibly and safely reopening schools.
\end{abstract}

Keywords: Coronavirus, COVID-19, Education, Pandemic, Quarantine, Reopening, School, Disease Control Strategies, Safety, Children, Children's Health

\section{Introduction}

"Plans are worthless, but planning is everything." (United States President Dwight Eisenhower)

Given the impact of the coronavirus disease 2019 (COVID-19) pandemic on every facet of society, the quote from the late President Eisenhower speaks to the need to rigorously think through operations and be adaptable. Kindergarten through Grade 12 (K-12) schools were closed in early March, 2020 across the United States. Given the high individual and societal costs of these closures, as well as the adverse impact of school closure on children's growth and mental health, nations have placed a high priority on reopening schools. Planning for school reopening as COVID-19 case numbers have remained high in many U.S. states presents challenges. The unique nature of each school must be considered and will require a tailored solution for each geographic zone. This article aims to present general guidance that can be adapted by K-12 schools as they develop a safe reopening plan that will consider the needs of the children, their families, and staff at the 
school. Information provided in this paper is not a comprehensive guide, nor are requirements or standards presented.

COVID-19 is an infectious disease caused by a coronavirus identified in late 2019, the so-called severe acute respiratory syndrome coronavirus 2 (SARS-CoV-2). The virus is primarily spread is by respiratory droplets among close contacts. Aerosol transmission can also occur in indoor, crowded, and inadequately ventilated areas. Respiratory aerosols are characterized by a diameter of fewer than 5 micrometers $(\mu \mathrm{m})$, while droplets are larger (Milton 2020). Evidence strongly suggests that the COVID-19 virus can be transmitted through fomites and contact with contaminated surfaces (Santarpia 2020).

Approximately 15 to $45 \%$ of SARS-CoV-2 infections are asymptomatic cases (Nishiura et al. 2020). Individuals infected before being symptomatic are termed "presymptomatic". They may harbor high viral loads before they feel ill, potentially transmitting viruses efficiently. The role that asymptomatic cases play in the transmission of SARSCoV-2 is unclear, given their typically lower viral loads (Vermund and Pitzer 2020). One may speculate that lower efficiency of transmission per encounter could still add up to a high transmission burden due to more encounters taking place since an asymptomatic person is less likely to physical distancing compared to a person who feels ill.

While children can be infected with SARS-CoV-2, the incidence of COVID-19 disease in children is lower compared to adults; children who contract COVID-19 are more likely

to remain without symptoms or have moderate symptoms (Dong et al. 2020). Youth deaths are less frequent than they are represented in the general population (Dong et al. 2020). One hypothesis suggests that milder cases of this disease in children may be attributable to lower levels of angiotensin-converting enzyme 2 (ACE2) gene expression in children compared to adults. Rarely, children may present with the multisystem inflammatory syndrome in children (MIS-C). MIS-C is a condition where different organs become inflamed, including the heart, lungs, kidneys, brain, skin, eyes, or gastrointestinal organs. Fortunately, COVID-19 related MIS-C is extremely rare, with an incidence of 2 per 100,000, and it is treatable with symptomatic and anti-inflammatory measures (Henderson et al. 2020).

Children and adolescents tend to have closer interactions with each other compared to older age groups and younger children may be less likely to follow guidance on mask use and proper hand hygiene. Adult supervision and regular positive encouragement of safe personal behaviors are required to promote adherence to recommended COVID-19 public health practices. Children are likely to spread the virus to more vulnerable individuals in their close contacts or households (Somekh et al. 2020). Controlling disease outbreaks in children is likely crucial to protect the well-being of the community as a whole. Effective planning of administrative and engineering controls for risk reduction, communication across the school community, and partnerships with local public health organizations are all key to effective disease prevention.

Disease control can be categorized as approaches that are directed by the school administration (top-down) and those that are dependent on the personal behaviors of students, teachers, and administrative staff in the school (bottom-up) (Figure 1). Top-down approaches include the elimination of physical contact, administrative controls, and engineering controls, ranked in decreasing order of effectiveness of reducing transmission risks. Bottom-up approaches are focused on individual-level actions such as face masks use and good hand hygiene, cleaning, and disinfection behaviors. No single control measure will eliminate infectious disease risk. Layering multiple strategies from both approaches is critical in creating a safer school environment during the COVID-19 pandemic. 
In this article, we introduce key issues in COVID-19 and school reopening. We will discuss guiding principles and the hierarchy of disease control related to school reopening in a respiratory viral pandemic. The application of these safety principles will also be discussed for specific school spaces in the supplement. Finally, we will highlight special considerations for vulnerable student populations and school mental health support in a pandemic.

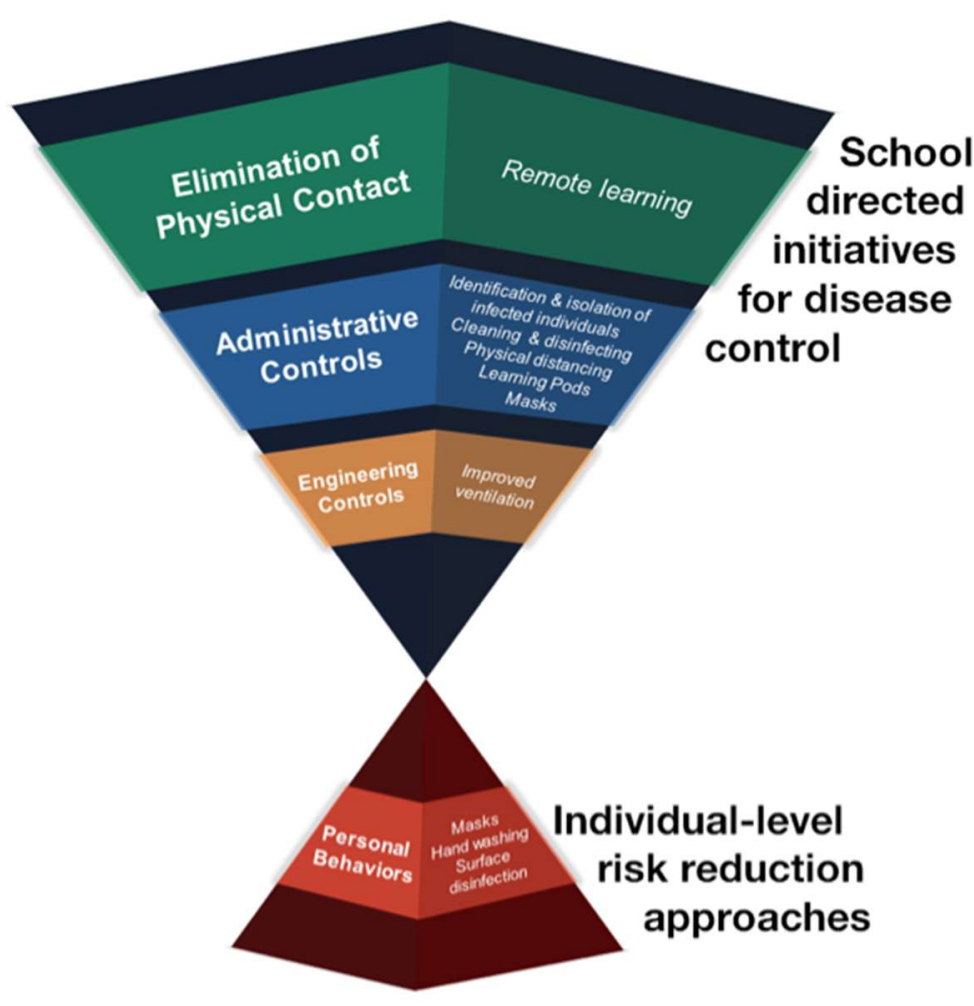

Figure 1. School directed (top-down) and student/teacher (bottom-up) risk reduction strategies to decrease disease transmission.

\section{School Directed Initiatives for Disease Control}

\subsection{Elimination of physical contact}

Eliminating physical contact is the most effective method to reduce the risk of disease transmission (National Institute for Occupational Safety and Health 2020a; American Society of Safety Professionals 2020), which requires shifting learning to a virtual format -- a challenge for many schools. The development of a virtual learning program is essential to accommodate students and teachers who are at high-risk for COVID-19 infection. In-person courses should be prioritized for academic experiences that cannot be achieved virtually. Teachers and parents may benefit from training sessions discussing effective remote learning techniques. The school should be aware of students without access to a computer with high-speed internet and provide necessary support. Remote learning can be a powerful tool that offers students and teachers the safety of learning from home while mitigating the harms of foregoing the in-person academic experience.

\subsection{Vaccination}

Vaccination is the most effective and safest intervention to prevent infectious diseases. Vaccines contain a weakened version or a component of a disease-causing microorganism, which stimulates one's adaptive immunity, acting as the first exposure to the organism without making one sick. Getting a flu vaccine is especially important during the pandemic, as it will reduce the burden of flu illnesses (which have similar symptoms to 
COVID-19) and conserve scarce medical resources for the care of COVID-19 patients. When COVID-19 vaccination becomes available to the school members, it is critical for the schools to take the initiative and get as many members vaccinated as possible. Parent education, combined with school-based vaccination-clinics, raises the vaccination rate significantly. Schools should be encouraged to require vaccinations for in-person attendance. These school entry laws have been effective in increasing vaccination compliance.

\subsection{Administrative controls}

The risk of infection can be minimized through the implementation of school-initiated administrative controls. These control measures as related to academics, logistics, and school staff/teachers/visitors are summarized in Figure 2.

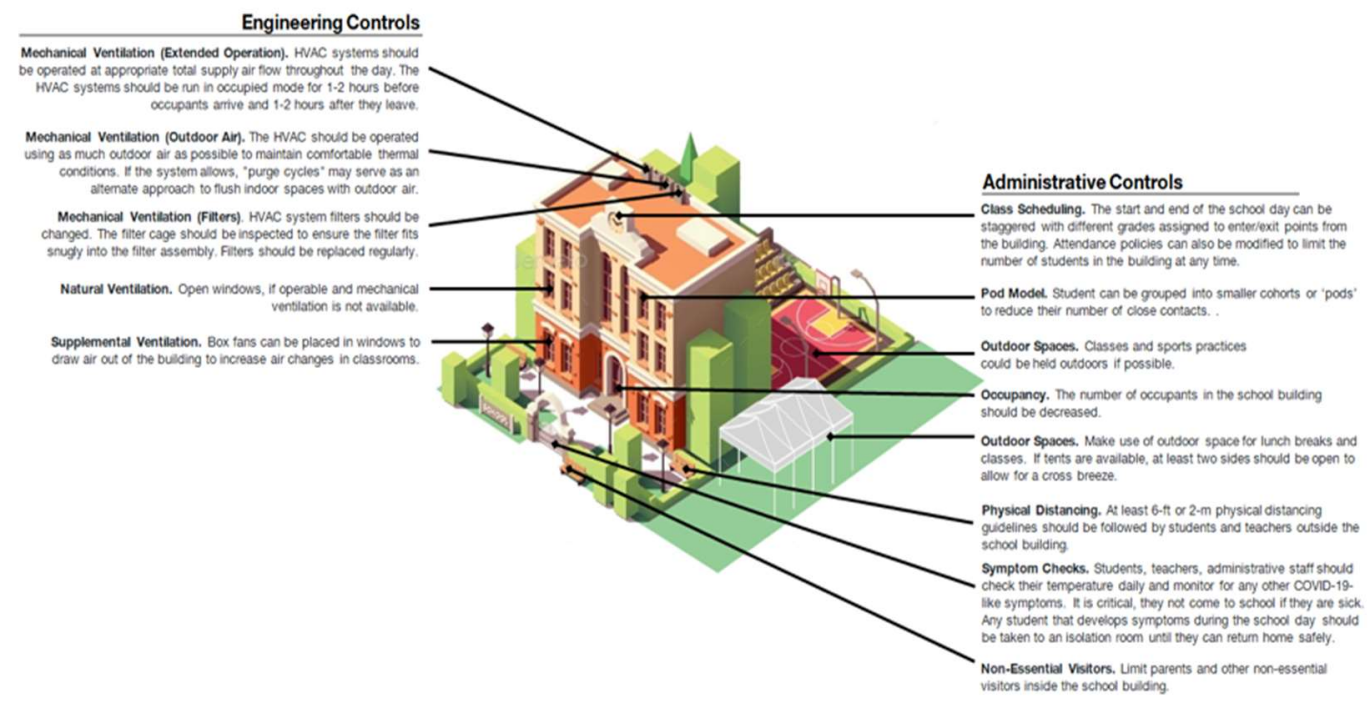

Figure 2. Administrative and engineering controls that can be implemented across the school to reduce risk of disease transmission.

\subsubsection{Academics}

The academic calendar and class schedule should be adjusted to maximize physical distancing at all times. Staggering and extended arrival/departure times, recess, lunchtimes, and locker access are all potential strategies to minimize people interaction. Extended recess allows staff to provide air ventilation time between different groups of students. Having a hybrid schedule in which students take virtual classes for a portion of the week and in-personal classes for the remainder of time may be useful to reduce occupancy. Holidays like fall breaks can be readjusted to avoid travel during the semester.

\subsubsection{1.".Pod" model}

Smaller cohorts or 'pods' can be created to limit class sizes and large-group interactions (Connecticut State Department of Education 2020; Moroney 2020; North 2020; Cullotta 2020; Moyer 2020). Each pod can eat, have classes and perform school activities together. If a student within a pod becomes sick, this model reduces the risk of a larger outbreak across the wider school community. Pod size can be strategically adjusted based on the different learning and social needs of different age groups. The number of students in each pod must balance both adherence to guidelines and also transmission control. If possible, setting up different entrances, exits, or buildings for different pods can help to mitigate risk further. Asking each pod to use the same classrooms and teachers to rotate between spaces can minimize item-sharing and people-mixing.

\subsubsection{Activities}


Activities present challenges as students from across the school community have the potential to interact. Large student gatherings with prolonged close contact in indoor spaces are also present higher risk. Some examples include school assemblies, field trips, arts events (e.g., drama, music, dance), sports events, and "homecoming" (common in the United States). These higher-risk gatherings should be held in a virtual online format to maintain the students' social networks while reducing risks for the school community.

\subsubsection{Logistics}

\subsubsection{Physical distancing}

Physical distancing requires individuals to maintain a safe distance from others to limit disease transmission (Centers for Disease Control and Prevention 2020a). This has also been called "social distancing", which is imprecise with unfavorable connotations of social isolation. Six feet of distance has been suggested following droplet deposition dynamics (Santarpia et al. 2020; Bi et al. 2020). Accounting for aerosol transmission necessitates increased physical distancing, in particular for higher-risk indoor environments (i.e., music rooms, cafeterias) (Prather et al. 2020). Schools can implement various strategies to achieve physical distancing. Removing extra furniture from classrooms can free up floor space.

\subsubsection{Cleaning and disinfecting}

Scheduled disinfecting and cleaning is essential to reduce the risk of viral transmission from commonly touched surfaces. Those that appear to be dirty must be cleaned before being disinfected. Recommended disinfectants for use against SARS-CoV-2 have been compiled by the United States Environmental Protection Agency (EPA) (United States Environmental Protection Agency 2020). The school's COVID-19 coordinator can monitor and maintain the school's inventory of personal protective equipment, hand sanitizers, disinfection wipes, soap, paper towels, and other cleaning and disinfection products. Custodial staff training on the proper use of disinfectants (i.e., sufficient contact time) and personal protective equipment is necessary. Limited-touch options (i.e., sensor-activated, foot-operated pedals) can further reduce disease transmission. If one is suspected to be COVID-19 positive, access to any spaces recently used by this individual should be restricted until thorough cleaning and disinfection is completed.

\subsubsection{Noise}

Sound level is a proxy for aerosol release -- speaking loudly, yelling, or shouting can release more aerosols (Asadi et al. 2020; Asadi et al. 2019). Visual displays of sound levels are also available in the form of a traffic light. The National Institute for Occupational Safety and Health (NIOSH) Sound Level Meter is an available app that can indirectly inform and remind students to keep sound levels low (National Institute for Occupational Safety and Health 2020b).

\subsubsection{Symptom checks}

COVID-19 symptom-check apps are powerful tools to remind students and teachers to report symptoms and check their daily temperature. The apps can notify the school officials when a COVID-19-like symptom arises, allowing immediate actions to encourage students to stay at home, conduct testing, and conduct contact tracing. These apps can also record student attendance, movement, family member attendance, and parent and teacher communications. These data allow the immediate identification of high-risk individuals. While convenient, the use of these apps requires access to a digital oral thermometer, which presents challenges for some low-resource school communities. For schools without apps, conducting non-touch temperature checks before students enter the school building may help mitigate risks. However, a warmly bundled child in a cold winter may 
run a transient higher fever simply from warming; similarly, a child having walked to school on a hot day may also have a transient low-grade elevated temperature. Sending healthy students ("false positives") home will be disruptive for both families and schools so sitting a child in a quiet, temperature-controlled setting for ten minutes and then rechecking the temperature is advisable.

\subsubsection{Testing and quarantine}

We recommend that schools have the necessary devices and medical supplies to monitor symptoms. If a student becomes sick while in school or shows any COVID-19 symptoms upon arrival, the student must be isolated until a parent or guardian comes to guide the student off the school property. Access to personal protective equipment (PPE) is crucial for school staff when interacting with a potentially ill student.

Anyone who might have been exposed to a potentially infected individual should be notified and quarantined immediately. The United States Centers for Disease Control and Prevention considers contact to be the proximity of fewer than 6 feet for at least 15 minutes. Anyone who qualifies as a contact must be quarantined. If a case is confirmed, the responsible school official must file a report to the local health department. Parents or guardians and the student's pediatrician must be notified immediately so that an ill child can return home for at least 14 days of isolation. Medical attention is needed for children with severe illness. Furthermore, education on prevention strategies must be provided to avoid a family cluster outbreak.

For boarding schools, all students and staff arriving on the school campus are recommended to be "gateway" tested. Ideally, a test within four days prior to arrival followed by 14 days of quarantine and repeat testing at day 12-13 or so would help eliminate falsenegative cases and those that are incubating. Or, students should get tested during the first full day of arrival, and get another test no sooner than 4 days after the first screening test. Students should quarantine until they receive two negative COVID-19 test results. The schools may need to quarantine students in their rooms, until the test results are confirmed as negative. Food should be delivered, and laundry facilitated. Particularly limited use schedules for bathroom and shower use, with students or staff helping clean bathrooms after use, is advised. Any student must be re-tested if presenting with any symptom or exposure (contact definition of fewer than six feet for at least 15 minutes) to infected individuals. Boarding schools and colleges/universities can also track epidemiologic trends across the county to judge the needed frequency of routine testing (Centers for Disease Control and Prevention 2020b).

\subsubsection{Teachers, staff, and visitors}

\subsubsection{Workforce and communications}

School operation is contingent on faculty and staff resuming their teaching and administrative responsibilities. These individuals also play a critical role in mitigating risks through continued communication of disease control strategies to students and the supervision of students to ensure safe personal behavior. Being good role models and communicating with all school personnel daily can help reinforce health messages. Regular meetings can be held to evaluate the intervention plans and strategies, reinforce safety principles, and community/school health status updates. Sending reminders can reduce risks and build consumer confidence in the efforts being made to keep children and staff safe. Teachers and staff need to stay home if they feel sick. Schools should anticipate that the number of days taken for sick leave over the academic year is likely to be higher than in the past. It may be necessary to remove any barriers for taking additional leave from school, such as medical documentation (Edwards et al. 2019). It is important for schools to build the necessary staffing capacity to fulfill these responsibilities and to fill any staffing gaps that may arise without exacerbating crowding. 


\subsubsection{Non-essential visitors}

Visitor access should be restricted inside the school building, with a designated outside pick-up area for parents/guardians. In exceptional circumstances, all visitors must be chaperoned and need to wear a face mask that covers their nose and mouth. Establishing a time and location limit for visitors can also be useful in reducing risks.

\subsection{Engineering Controls}

Establishing well-ventilated school buildings is essential in reducing risks associated with the airborne transmission of SARS-CoV-2. Poorly ventilated indoor spaces can lead to increased exposure of virus-laden aerosols. Engineering controls can be implemented in a school to improve ventilation through (i), increasing the amount of outdoor air introduced into the building; (ii), improving filtration of recirculated air; (iii), increased the volume of air exchange per hour; and (iv), use of supplementation controls in individual classrooms, such as portable air cleaners and window-mounted box fans. The optimal configuration of controls will be unique to each school. Figure 3 presents a flow diagram to evaluate potential risk reduction controls that may be feasible based on the school's existing infrastructure.

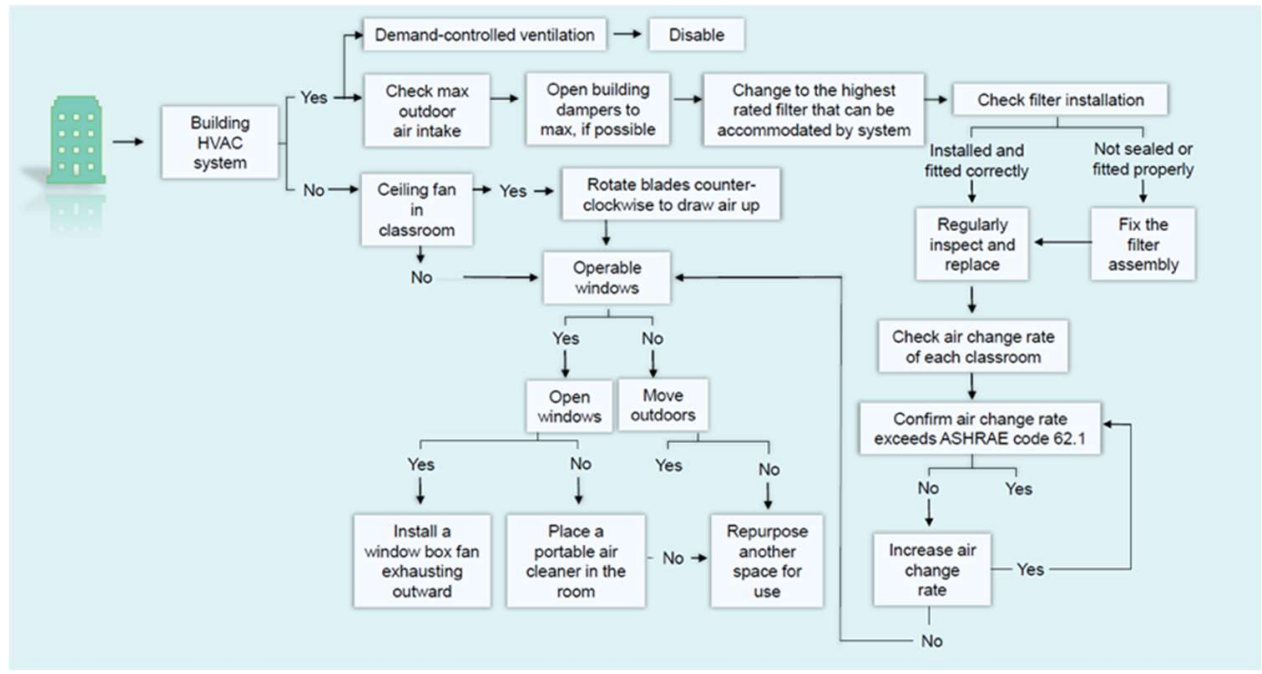

Figure 3. Engineering control flow diagram for optimizing ventilation in schools.

\subsubsection{Mechanical ventilation}

School buildings that are equipped with heating, ventilation, and air conditioning (HVAC) system are recommended to discuss current operation protocols and system capabilities with facility managers or an HVAC professional. The HVAC system must be commissioned before school reopening to verify the expected performance: commissioning will confirm that: (i), filters, dampers, as well as economizers seals and frames are intact, clean, functional, and responsive to control signals; (ii), temperature and relative sensors are appropriately calibrated and communicating with the building automation system; and (iii), air handling systems are providing sufficient airflow to individual rooms and exhaust fans are functional and venting outdoors.

The operation of ventilation systems with $100 \%$ outdoor air, eliminating recirculation of viral material in the building, offers the most significant risk reduction concerning engineering controls. However, during extreme weather, or for regions with extreme hot or cold temperatures, increased outdoor air use may be challenging to maintain thermal comfort for school occupants, and may introduce issues to the HVAC coils. Adjusting building temperature set points to parallel outdoor conditions will enable effective use of outdoor air and provide an additional option for disease control. Buildings with HVAC 
systems that cannot accommodate $100 \%$ outdoor air may decide to run a short (10 to 15 minute) $100 \%$ outdoor air purge cycle during the day (i.e., after or during the lunch break). Schools running their HVAC system using less than $100 \%$ outdoor air will recirculate some amount of air. Some HVAC systems are designed to adjust air flows in individual classrooms and offices automatically based on occupancy load monitored using carbon dioxide sensors. Demand-controlled ventilation sequences need to be disabled to maintain HVAC operation at maximum air flows independent of the number of students, teachers, and administrative staff in the school building.

In the HVAC's air handling unit, filters can be used as the first line of defense in removing virus-laden aerosol from recirculated air. Minimum Efficiency Reporting Value (MERV) is often used to evaluate the performance of air filters at removing different types of particles. MERV13 rated filters has 90\% single-pass removal efficiency of aerosol sized between 0.3 and $1 \mu \mathrm{m}$ diameter (Azimi and Stephens 2013), it has been recommended for use in HVAC systems as a risk reduction strategy for COVID-19 (American Society of Heating Refrigerating and Air-Conditioning Engineers 2020a). If possible, filters should be upgraded to the highest-rated filter (i.e., High-Efficiency Particulate Air filters) that can be accommodated by the system. While a MERV13 filter is recommended for use, it is important to ensure that a building's HVAC system can accommodate the necessary flow required by a higher rated filter.

Beyond simply upgrading and periodically changing the system's filter, it is also critical to ensure the filter cage is maintained; any gaps in the housing assembly will impair filter efficiency. Regular inspection of the filter and filter assembly, as well as following manufacturer recommended maintenance, are critical to ensure proper operation. Filter changes are recommended to be carried after a period with no or less building occupancy (i.e., weekend, holiday) following findings from studies evaluating the stability of SARSCoV-2 on surfaces (van Doremalen et al. 2020). When it is possible, a 10\% bleach solution or another appropriate disinfectant can be used for disinfecting filters before removal. Once removed, filters can be placed into a bag for disposal as general waste.

Increasing the number of air changes in a classroom will allow for sequential removal of airborne viral material on each pass through the filter. The number of air changes per hour $(\mathrm{ACH})$ in an indoor space can also be increased to enhance ventilation. ACH should be evaluated for each classroom in relation to the size of the room and occupants' activities. The amount of airflow into each schoolroom should ideally exceed the minimum American Society of Heating, Refrigerating, and Air-Conditioning Engineers (ASHRAE) standards with a goal of 5 to $6 \mathrm{ACH}$.

HVAC systems in some school buildings may have displacement ventilation capabilities. This system feature introduces conditioned air at a low flow from supply diffusers positioned near the floor and exhaust air near the ceiling to provide enhanced air mixing. The use of displacement ventilation in classrooms and offices is another effective engineering control that provides enhanced air mixing, moving potential contaminant air from students and teachers.

\subsubsection{Natural ventilation}

For buildings using natural ventilation, operable windows, doors, skylight, or roof ventilators can be opened when outside temperatures and humidity levels permit. In buildings with an HVAC system, the interlock with the windows should be disabled in the building automation system. Portable air cleaners can be used in lieu of HVAC systems when outside air is too hot or too cold.

\subsubsection{Supplemental controls}


Air purifiers, window-mounted box fans, and ultraviolet germicidal irradiation (UVGI) are supplemental controls that have been used in various indoor environments to reduce virus-laden aerosol. Supplemental controls can be used in combination with other risk reduction strategies, as guided by the flow diagram shown in Figure 3.

\subsubsection{Unintended exposures from outdoor environments}

While maximizing outdoor airflow is recommended in indoor spaces, it is important to be aware of potential contaminants in outdoor air and take precautions that minimize/prevent school occupants from exposure. For buildings with mechanical ventilation, outdoor air inlets should not be positioned near exhaust air outlets to avoid re-entry of potentially contaminated air. In schools using natural ventilation, outdoor airborne contaminants can readily enter the building spaces through open windows, including air pollutants derived from traffic and industrial sources, allergens, pests, and insects. It will be important to consider potential exposure to these contaminants and be selective on which operable windows are used. Considering the potential exposure of students and teachers, exposure to these outdoor factors is also important if scheduling outdoor classes.

\subsubsection{Sensors to monitor building performance}

Achieving the optimal performance of an HVAC system requires regular commissioning. Indirect measures of system performance can also be evaluated using air pollutant sensors. Carbon dioxide sensors can provide useful information about occupancy load and activity levels in relation to the ventilation capacity of the classroom. Airflow may require adjustments if levels of exhaled carbon dioxide steadily increase while occupants are in the space. Additional sensors are available to evaluate ventilation of air pollutants from other sources such as particulate matter $2.5 \mu \mathrm{m}$ or less in diameter, and volatile organic compound sensors.

\section{Student and Teacher-Directed Risk Reduction Strategies}

COVID-19 public health guiding principles include physical distancing, hand/face/surface hygiene, use of face masks covering the nose and mouth, improved air quality and ventilation, and appropriate testing and follow-up (isolation, quarantine, and contract tracing). Adherence to all of these strategies is key to improving the safety of the school community. This section discusses how individual-directed principles may be applied.

\subsection{Masks}

There is strong evidence from epidemiology and economics that supports the use of masks to limit community spread of COVID-19. Face masks provide inward and outward protection. All members are recommended to wear face masks throughout the day while on school property (Centers for Disease Control and Prevention 2020a). Education on how to safely choose, wear, care for, clean or discard, and store masks can be useful to encourage adherence. Promoting personalized masks with the school logo or creating masks for students in different classes, houses, clubs, or sports teams may also encourage use. Fun masks for younger children may include favorite cartoon characters.

Masks made from cotton fabrics with high thread counts and random fiber orientation seem promising for preventing release and exposure to droplets and aerosols (Dbouk and Drikakis 2020). They are also highly cost-effective (Abaluck et al. 2020). In contrast, elastic fabric materials are not recommended due to the large pore size, resulting in lower filtration efficiency. Masks should be appropriately sized and provide complete coverage of both the nose and mouth (Centers for Disease Control and Prevention 2020c). Face masks with an exhalation valve are not recommended as they offer inward protection but no outward protection; thus, they will not prevent the spread of the virus from the mask 
wearer (Ippolito et al. 2020). Reusable masks can be washed or stored 2 to 3 days between use (Hao et al. 2020; Yang 2020; World Health Organization 2020a). Rotating between at least three masks will allow for safer reuse of masks. Face shields are not a replacement for marks. Face shields have limited utility for reducing risk toward airborne transmission (Perencevich et al. 2020). A face shield could be worn in addition to a mask, but face shields should not be worn without a mask unless substantial physical distancing is also possible.

In situations where masks cannot be worn (i.e., eating), other precautions can be taken to increase safety, such as using plexiglass to create a physical barrier. Alternative arrangements should also be made for students who are unable to wear a face mask due to developmental, respiratory, young age, or other physical conditions. Members of the school community must understand that wearing a mask is not a replacement for physical distancing or other guiding public health principles, or vice versa.

Masks can create challenges in certain pedagogical cases, such as language classes. Foreign language instructors may need to be seen by students to appreciate mouth movements needed to make certain sounds. Video assistance should be considered, or a shield combined with an increase in their physical distance to the students to 12 feet may be considered so that students can see the instructor mouthing the words to be learned. In these cases where teachers do not wear masks, the duration of the class time without a mask could be minimized, and additional engineering controls for ventilation can be used in the classroom to offer enhanced risk reduction approaches. In situations where lipreading is required, and physical distancing may make it impossible for the deaf or hard of hearing student to read lips, communication may be possible using a mask with a transparent mouth window. While not ideal, teachers using only face shields can stand near an portable air cleaner or window-mounted box fan. These lessons can be held outdoors, if the weather permits.

\subsection{Hand hygiene}

All students, teachers, and school administrators should be consistently reminded to wash their hands as frequently as possible. Hands should be washed with soap and water for at least 20-30 seconds. That is longer than most people realize, the time it takes to sing "Happy Birthday to You" twice. When lacking soap and water, hand sanitizer that contains at least $60 \%$ alcohol can be used. For hand sanitizer to be effective, all surfaces of the hands must be covered and then rubbed until dry. It is especially important for students, teachers, administrative staff to wash their hands after touching common surfaces or their face after they cough or sneeze, and after using the restroom (Pradhan et al. 2020). Courtesy greetings such as shaking of hands should not be avoided.

\section{Conclusion}

The fundamental principles for keeping schools safe are similar to those for any indoor environment during influenza season, but the needs of children and adolescents must be brought to the fore in this time of greater risk. These elements include universal mask use, physical distancing, hand hygiene for hands, optimized indoor air quality, outdoor teaching and activities whenever possible, limiting crowds, abundant testing, and enhanced supports for vulnerable students and adults. Universal influenza vaccine is highly advisable. Provision for temporary isolation or quarantine, along with contact tracing, is needed. Boarding schools, colleges, and universities that host students from far away may need to invoke their locum parentis and provide health care, quarantine, isolation, and contact tracing on behalf of distanced parents and guardians.

The feasibility of maximum safety will vary with local attitudes and resources. If political leaders, parents/guardians, educational administrators, or school staff do not take COVID-19 control seriously, much damage can occur if necessary, precautions are not taken appropriately. Improved air quality, masks, hand sanitizers, grab-and-go meals, 
outdoor tents, smaller class sizes, and accommodations for vulnerable individuals all take extra resources. Governments must acknowledge this and provide these resources in this time of COVID-19 before the availability of excellent treatments and vaccines.

The current crisis calls for a shift in culture that recommends universal, routine mask use. Behavioral adherence must be reinforced and incentivized. Vulnerable groups must be protected, whether students, vulnerable people living with the students, teachers, or other staff. Mitigation measures hopefully enable us to open up schools in lower incidence settings around the world. Virtual online learning has become the preferred method of education in the face of high viral transmission in a school's particular community.

\section{References}

Abaluck J, Chevalier J, Christakis NA, et al. The case for universal cloth mask adoption and policies to increase supply of medical masks for health workers. Covid Economics 2020; Issue 5 (16 April, 2020): pp. 147-159. https://cepr.org/sites/default/files/news/CovidEconomics5.pdf

American Society of Heating Refrigerating Air-Conditioning Engineers (2019) Ventilation for Acceptable Indoor Air Quality in Residential Buildings. vol ANSI/ASHRAE Standard 62.1-2019 ANSI/ASHRAE, Atlanta, GA, USA

American Society of Heating Refrigerating and Air-Conditioning Engineers (2019) Ultraviolet Air and Surface Treatment. 2019 ASHRAE Handbook. Atlanta, GA, USA

American Society of Heating Refrigerating and Air-Conditioning Engineers (2020a) Reopening of Schools and Universities. American Society of Heating, Refrigerating and Air-Conditioning Engineers https://www.ashrae.org/technical-resources/reopening-ofschools-and-universities.

American Society of Heating Refrigerating and Air-Conditioning Engineers (2020b) Reopening Schools and Universities Guidance. American Society of Heating, Refrigerating and Air-Conditioning Engineers, Atlanta, GA, USA

American Society of Safety Pofessionals (2020) How to Apply the Hierarchy of Controls in a Pandemic. American Society of Safety Pofessionals https://www.assp.org/news-and-articles/2020/03/31/how-to-apply-the-hierarchy-of-controls-in-a-pandemic.

Araujo FJO, de Lima LSA, Cidade PIM, Nobre CB, Neto MLR (2020) Impact Of Sars-Cov-2 And Its Reverberation In Global Higher Education And Mental Health. Psychiatry Res 288:112977. doi:10.1016/j.psychres.2020.112977

Asadi S, Bouvier N, Wexler AS, Ristenpart WD (2020) The coronavirus pandemic and aerosols: Does COVID-19 transmit via expiratory particles? Aerosol Sci Technol 0 (0):1-4. doi:10.1080/02786826.2020.1749229

Asadi S, Wexler AS, Cappa CD, Barreda S, Bouvier NM, Ristenpart WD (2019) Aerosol emission and superemission during human speech increase with voice loudness. Sci Rep 9 (1):2348. doi:10.1038/s41598-019-38808-z

Association of Home Appliance Manufacturers (2020) Air Fltration Standards Association of Home Appliance Manufacturers. https://ahamverifide.org/ahams-air-filtration-standards/.

Azimi P, Stephens B (2013) HVAC filtration for controlling infectious airborne disease transmission in indoor environments: Predicting risk reductions and operational costs. Build Environ 70:150-160. doi:10.1016/j.buildenv.2013.08.025

Banerjee A, Kulcsar K, Misra V, Frieman M, Mossman K (2019) Bats and Coronaviruses. Viruses 11 (1). doi:10.3390/v11010041

Barratt H, Kirwan M, Shantikumar S (2010) Epidemiology. Public Health Textbook. Public Health Action Support Team, UK

Beggs CB, Kerr KG, Donnelly JK, Sleigh PA, Mara DD, Cairns G (2000) The resurgence of tuberculosis in the tropics. An engineering approach to the control of Mycobacterium tuberculosis and other airborne pathogens: a UK hospital based pilot study. Trans R Soc Trop Med Hyg 94 (2):141-146. doi:10.1016/s0035-9203(00)90250-5

Bi Q, Wu Y, Mei S, Ye C, Zou X, Zhang Z, Liu X, Wei L, Truelove SA, Zhang T, Gao W, Cheng C, Tang X, Wu X, Wu Y, Sun B, Huang S, Sun Y, Zhang J, Ma T, Lessler J, Feng T (2020) Epidemiology and transmission of COVID-19 in 391 cases and 1286 of their close contacts in Shenzhen, China: a retrospective cohort study. The Lancet Infectious Diseases 20 (8):911-919. doi:10.1016/s14733099(20)30287-5 
Cao W, Fang Z, Hou G, Han M, Xu X, Dong J, Zheng J (2020) The psychological impact of the COVID-19 epidemic on college students in China. Psychiatry Res 287:112934. doi:10.1016/j.psychres.2020.112934

Centers for Disease Control and Prevention (2020a) How to Protect Yourself \& Others. Coronavirus Disease 2019 (COVID-19). Centers for Disease Control and Prevention Atlanta, GA, USA

Centers for Disease Control and Prevention (2020b) Interim Considerations for K-12 School Administrators for SARS-CoV-2 Testing. Coronavirus Disease 2019 (COVID-19). Centers for Disease Control and Prevention, Atlanta, GA, USA

Centers for Disease Control and Prevention (2020c) Use of Masks to Help Slow the Spread of COVID-19. Coronavirus Disease 2019 (COVID-19). Centers for Disease Control and Prevention Atlanta, GA, USA

Chen S, Li F, Lin C, Han Y, Nie X, Portnoy RN, Qiao Z (2020) Challenges and recommendations for mental health providers during the COVID-19 pandemic: the experience of China's First University-based mental health team. Global Health 16 (1):59.

doi:10.1186/s12992-020-00591-2

Cohen AK, Hoyt LT, Dull B (2020) A Descriptive Study of Coronavirus Disease 2019-Related Experiences and Perspectives of a National Sample of College Students in Spring 2020. J Adolesc Health. doi:10.1016/j.jadohealth.2020.06.009

Connecticut State Department of Education (2020) Adapt, Advance, Achieve: Connecticut's Plan to Learn and Grow Together. Connecticut State Department of Education, CT, USA

Courtney D, Watson P, Battaglia M, Mulsant BH, Szatmari P (2020) COVID-19 Impacts on Child and Youth Anxiety and Depression: Challenges and Opportunities. Can J Psychiatry:706743720935646. doi:10.1177/0706743720935646

Cullotta KA (2020) 'Pandemic pods' and 'micro-schools': How parents are finding ways to help their kids - and themselves manage schooling at home. Chicago Tribune, 2020/07/28,

Dbouk T, Drikakis D (2020) On respiratory droplets and face masks. Phys Fluids (1994) 32 (6):063303. doi:10.1063/5.0015044

Delamater PL, Street EJ, Leslie TF, Yang YT, Jacobsen KH (2019) Complexity of the Basic Reproduction Number (R0). Emerg Infect Dis 25 (1):1-4. doi:10.3201/eid2501.171901

Dong Y, Mo X, Hu Y, Qi X, Jiang F, Jiang Z, Tong S (2020) Epidemiology of COVID-19 Among Children in China. Pediatrics 145 (6). doi:10.1542/peds.2020-0702

Duan L, Shao X, Wang Y, Huang Y, Miao J, Yang X, Zhu G (2020) An investigation of mental health status of children and adolescents in china during the outbreak of COVID-19. J Affect Disord 275:112-118. doi:10.1016/j.jad.2020.06.029

Edwards CH, Tomba GS, Sonbo Kristiansen I, White R, de Blasio BF (2019) Evaluating costs and health consequences of sick leave strategies against pandemic and seasonal influenza in Norway using a dynamic model. BMJ Open 9 (4):e027832. doi:10.1136/bmjopen-2018-027832

Foarde KK (2010) Development of a Method for Measuring Single-Pass Bioaerosol Removal Efficiencies of a Room Air Cleaner. Aerosol Science and Technology 30 (2):223-234. doi:10.1080/027868299304804

Hao W, Parasch A, Williams S, Li J, Ma H, Burken J, Wang Y (2020) Filtration performances of non-medical materials as candidates for manufacturing facemasks and respirators. International Journal of Hygiene and Environmental Health 229:113582.

doi:10.1016/j.ijheh.2020.113582

Henderson LA, Canna SW, Friedman KG, Gorelik M, Lapidus SK, Bassiri H, Behrens EM, Ferris A, Kernan KF, Schulert GS, Seo P, MB FS, Tremoulet AH, Yeung RSM, Mudano AS, Turner AS, Karp DR, Mehta JJ (2020) American College of Rheumatology Clinical Guidance for Pediatric Patients with Multisystem Inflammatory Syndrome in Children (MIS-C) Associated with SARS-CoV-2 and Hyperinflammation in COVID-19. Version 1. Arthritis Rheumatol. doi:10.1002/art.41454

Huckins JF, daSilva AW, Wang W, Hedlund E, Rogers C, Nepal SK, Wu J, Obuchi M, Murphy EI, Meyer ML, Wagner DD, Holtzheimer PE, Campbell AT (2020) Mental Health and Behavior of College Students During the Early Phases of the COVID-19 Pandemic: Longitudinal Smartphone and Ecological Momentary Assessment Study. J Med Internet Res 22 (6):e20185. doi:10.2196/20185 
Ippolito M, Iozzo P, Gregoretti C, Grasselli G, Cortegiani A (2020) Facepiece filtering respirators with exhalation valve should not be used in the community to limit SARS-CoV-2 diffusion. Infect Control Hosp Epidemiol:1-2. doi:10.1017/ice.2020.244

Jordan RE, Adab P, Cheng KK (2020) Covid-19: risk factors for severe disease and death. BMJ 368:m1198. doi:10.1136/bmj.m1198

Kettleson EM, Ramaswami B, Hogan CJ, Jr., Lee MH, Statyukha GA, Biswas P, Angenent LT (2009) Airborne virus capture and inactivation by an electrostatic particle collector. Environ Sci Technol 43 (15):5940-5946. doi:10.1021/es803289w

Knowlton SD, Boles CL, Perencevich EN, Diekema DJ, Nonnenmann MW (2018) Bioaerosol concentrations generated from toilet flushing in a hospital-based patient care setting. Antimicrob Resist Infect Control 7:16. doi:10.1186/s13756-018-0301-9

Kujundzic E, Hernandez M, Miller SL (2007) Ultraviolet germicidal irradiation inactivation of airborne fungal spores and bacteria in upper-room air and HVAC in-duct configurations. Journal of Environmental Engineering and Science 6 (1):1-9. doi:10.1139/s06039

Kujundzic E, Matalkah F, Howard CJ, Hernandez M, Miller SL (2006) UV air cleaners and upper-room air ultraviolet germicidal irradiation for controlling airborne bacteria and fungal spores. J Occup Environ Hyg 3 (10):536-546. doi:10.1080/15459620600909799

Lemecha Obsu L, Feyissa Balcha S (2020) Optimal control strategies for the transmission risk of COVID-19. J Biol Dyn 14 (1):590607. doi:10.1080/17513758.2020.1788182

Lindsley WG, Noti JD, Blachere FM, Szalajda JV, Beezhold DH (2014) Efficacy of face shields against cough aerosol droplets from a cough simulator. J Occup Environ Hyg 11 (8):509-518. doi:10.1080/15459624.2013.877591

Loades ME, Chatburn E, Higson-Sweeney N, Reynolds S, Shafran R, Brigden A, Linney C, McManus MN, Borwick C, Crawley E (2020) Rapid Systematic Review: The Impact of Social Isolation and Loneliness on the Mental Health of Children and Adolescents in the Context of COVID-19. J Am Acad Child Adolesc Psychiatry. doi:10.1016/j.jaac.2020.05.009

Luongo JC, Miller SL (2016) Ultraviolet germicidal coil cleaning: Decreased surface microbial loading and resuspension of cell clusters. Building and Environment 105:50-55. doi:10.1016/j.buildenv.2016.05.024

McDermott CV, Alicic RZ, Harden N, Cox EJ, Scanlan JM (2020) Put a lid on it: Are faecal bio-aerosols a route of transmission for SARS-CoV-2? J Hosp Infect. doi:10.1016/j.jhin.2020.04.024

Miller-Leiden S, Lobascio C, Nazaroff WW, Macher JM (1996) Effectiveness of in-room air filtration and dilution ventilation for tuberculosis infection control. J Air Waste Manag Assoc 46 (9):869-882. doi:10.1080/10473289.1996.10467523

Moroney M (2020) More Parents Are Considering Microschools Amid COVID-19: Here's What They Entail. PopSugar Inc. https://www.popsugar.com/family/what-are-coronavirus-school-pods-47639027.

Moyer MW (2020) Pods, Microschools and Tutors: Can Parents Solve the Education Crisis on Their Own? The New York Times, 2020/7/22

Narayanan, S. R., \& Yang, S. (2020). Airborne Transmission of Virus-Laden Aerosols inside a Music Classroom: Effects of Portable Purifiers and Aerosol Injection Rates. medRxiv. doi: 10.1101/2020.12.19.20248374

National Institute for Occupational Safety and Health (2020a) Hierarchy of Controls. Workplace Safety \& Health Topics. National Institute for Occupational Safety and Health Atlanta, GA, USA

National Institute for Occupational Safety and Health (2020b) Noise and Hearing Loss Prevention. Workplace Safety and Health Topics. National Institute for Occupational Safety and Health Atlanta, GA, USA

Nishiura H, Kobayashi T, Miyama T, Suzuki A, Jung SM, Hayashi K, Kinoshita R, Yang Y, Yuan B, Akhmetzhanov AR, Linton NM (2020) Estimation of the asymptomatic ratio of novel coronavirus infections (COVID-19). Int J Infect Dis 94:154-155. doi:10.1016/j.ijid.2020.03.020

North A (2020) Pandemic learning "pods" don't have to be just for the rich. Vox.com.

https://www.vox.com/2020/7/28/21340222/learning-pods-covid-private-pandemic-education-school. 
Oran DP, Topol EJ (2020) Prevalence of Asymptomatic SARS-CoV-2 Infection: A

Narrative Review. Ann Intern Med. 2020 Jun 3:M20-3012. doi: 10.7326/M20-3012. Epub ahead of print.

Paltiel AD, Zheng A, Walensky RP. Assessment of SARS-CoV-2 Screening Strategies to Permit the Safe Reopening of College Campuses in the United States (2020) JAMA Netw Open;3(7):e2016818.

Odriozola-Gonzalez P, Planchuelo-Gomez A, Irurtia MJ, de Luis-Garcia R (2020) Psychological effects of the COVID-19 outbreak and lockdown among students and workers of a Spanish university. Psychiatry Res 290:113108. doi:10.1016/j.psychres.2020.113108

Perencevich EN, Diekema DJ, Edmond MB (2020) Moving Personal Protective Equipment Into the Community: Face Shields and Containment of COVID-19. JAMA. doi:10.1001/jama.2020.7477

Phelps C, Sperry LL (2020) Children and the COVID-19 pandemic. Psychol Trauma 12 (S1):S73-S75. doi:10.1037/tra0000861

Pradhan D, Biswasroy P, Kumar Naik P, Ghosh G, Rath G (2020) A Review of Current Interventions for COVID-19 Prevention. Arch Med Res 51 (5):363-374. doi:10.1016/j.arcmed.2020.04.020

Prather KA, Wang CC, Schooley RT (2020) Reducing transmission of SARS-CoV-2. Science 368 (6498):1422-1424. doi:10.1126/science.abc6197

Reed NG (2010) The history of ultraviolet germicidal irradiation for air disinfection. Public Health Rep 125 (1):15-27.

doi:10.1177/003335491012500105

Santarpia JL, Rivera DN, Herrera V, Morwitzer MJ, Creager H, Santarpia GW, Crown KK, Brett-Major D, Schnaubelt E, Broadhurst MJ, Lawler JV, Reid SP, Lowe JJ (2020) Aerosol and Surface Transmission Potential of SARS-CoV-2.

medRxiv:2020.2003.2023.20039446. doi:10.1101/2020.03.23.20039446

Shaughnessy RJ, Levetin E, Blocker J, Sublette KL (1994) Effectiveness of Portable Indoor Air Cleaners: Sensory Testing Results. Indoor Air 4 (3):179-188. doi:10.1111/j.1600-0668.1994.t01-1-00006.x

Somekh I, Yakub Hanna H, Heller E, Bibi H, Somekh E (2020) Age-Dependent Sensory Impairment in Covid-19 Infection and Its Correlation with Ace2 Expression. Pediatr Infect Dis J. doi:10.1097/INF.0000000000002817

United States Environmental Protection Agency (2020) List N: Disinfectants for Use Against SARS-CoV-2 (COVID-19). United States Environmental Protection Agency Washington, D.C., USA

van Doremalen N, Bushmaker T, Morris DH, Holbrook MG, Gamble A, Williamson BN, Tamin A, Harcourt JL, Thornburg NJ, Gerber SI, Lloyd-Smith JO, de Wit E, Munster VJ (2020) Aerosol and Surface Stability of SARS-CoV-2 as Compared with SARS-CoV-1. N Engl J Med 382 (16):1564-1567. doi:10.1056/NEJMc2004973

Vermund SH (2020) Is classroom teaching advisable during COVID-19? With precautions, absolutely. The Connecticut Mirror, 2020/7/17, https://ctmirror.org/category/ct-viewpoints/is-classroom-teaching-advisable-during-covid-19-with-precautions-absolutely/

Vermund SH, Pitzer VE (2020) Asymptomatic transmission and the infection fatality risk for COVID-19: Implications for school reopening. Clin Infect Dis. doi:10.1093/cid/ciaa855

Wang C, Zhao H (2020) The Impact of COVID-19 on Anxiety in Chinese University Students. Front Psychol 11:1168. doi:10.3389/fpsyg.2020.01168

World Health Organization (2020a) Advice on the use of masks in the context of COVID-19. World Health Organization, Geneva, Switzerland

World Health Organization (2020b) Clinical management of COVID-19. COVID-19: Clinical care. World Health Organization, Geneva, Switzerland

Xiao H, Shu W, Li M, et al. (2020) Social Distancing among medical students during the 2019 coronavirus disease pandemic in China: Disease awareness, depression, anxiety, and behavioral activities. Int J Environ Res Public Health; 17(14):5047. 
Xu P, Peccia J, Fabian P, Martyny JW, Fennelly KP, Hernandez M, Miller SL (2003) Efficacy of ultraviolet germicidal irradiation of upper-room air in inactivating airborne bacterial spores and mycobacteria in full-scale studies. Atmospheric Environment 37 (3):405-419. doi:10.1016/s1352-2310(02)00825-7

Yang W (2020) Some new results on mask testing, thanks to @JTdavidhao It is reassuring the filtration efficiency didn't change much for fabrics after washing/drying cycles. N95 \& surgical masks are not for wash. Potential triboelectric charging in dried fabrics. Data: http://tinyurl.com/ve28f3l. Twitter.

Zhou SJ, Zhang LG, Wang LL, Guo ZC, Wang JQ, Chen JC, Liu M, Chen X, Chen JX (2020) Prevalence and socio-demographic correlates of psychological health problems in Chinese adolescents during the outbreak of COVID-19. Eur Child Adolesc Psychiatry 29 (6):749-758. doi:10.1007/s00787-020-01541-4

Zhou X (2020) Managing psychological distress in children and adolescents following the COVID-19 epidemic: A cooperative approach. Psychol Trauma 12 (S1):S76-S78. doi:10.1037/tra0000754 